Article

\title{
Miniaturized Salting-Out Assisted Liquid-Liquid Extraction Combined with Disposable Pipette Extraction for Fast Sample Preparation of Neonicotinoid Pesticides in Bee Pollen
}

\author{
Xijuan $\mathrm{Tu}^{1,2}$ and Wenbin Chen ${ }^{1,2, *(1)}$ \\ College of Bee Science, Fujian Agriculture and Forestry University, Fuzhou 350002, China; xjtu@fafu.edu.cn \\ 2 College of Animal Science, Fujian Agriculture and Forestry University, Fuzhou 350002, China \\ * Correspondence: wbchen@fafu.edu.cn
}

Academic Editors: Victoria Samanidou and Irene Panderi

Received: 12 November 2020; Accepted: 29 November 2020; Published: 3 December 2020

check for updates

\begin{abstract}
As the main source of nutrients for the important pollinator honeybee, bee pollen is crucial for the health of the honeybee and the agro-ecosystem. In the present study, a new sample preparation procedure has been developed for the determination of neonicotinoid pesticides in bee pollen. The neonicotinoid pesticides were extracted using miniaturized salting-out assisted liquid-liquid extraction (mini-SALLE), followed by disposable pipette extraction (DPX) for the clean-up of analytes. Effects of DPX parameters on the clean-up performance were systematically investigated, including sorbent types (PSA, C18, and silica gel), mass of sorbent, loading modes, and elution conditions. In addition, the clean-up effect of classical dispersive solid-phase extraction (d-SPE) was compared with that of the DPX method. Results indicated that PSA-based DPX showed excellent clean-up ability for the high performance liquid chromatography (HPLC) analysis of neonicotinoid pesticides in bee pollen. The proposed DPX method was fully validated and demonstrated to provide the advantage of simple and rapid clean-up with low consumption of solvent. This is the first report of DPX method applied in bee pollen matrix, and would be valuable for the development of a fast sample preparation method for this challenging and important matrix.
\end{abstract}

Keywords: sample preparation; disposable pipette extraction; neonicotinoid pesticides; bee pollen; HPLC; salting-out assisted liquid-liquid extraction

\section{Introduction}

As the most important managed pollinator, the honeybee is crucial to the ecosystem, agriculture, and food production. However, precipitous loss of the honeybee population has been reported in Europe and North America, which raises the concern of a pollination crisis [1]. Multiple stressors have been considered as potential causes of the honeybee decline, including nutrition, pesticide, parasites, and disease [2].

Bee pollen is the major source of protein in the honeybee diet, and it also provides the honeybee with essential nutrients, e.g., lipids, vitamins, and minerals [3]. In addition to nutritional values, phytochemicals in bee pollen were reported to be critical in the up-regulating detoxification and immunity genes of the western honeybee [4]. Thus, the security of bee pollen is important for keeping the honeybee healthy. However, bee pollen has the potential to be contaminated by pesticides due to the widespread use of chemicals in plant protection.

Determination of pesticide residues in bee pollen is important for evaluating the risk of exposure. Because of the complexity of the constituents in bee pollen, sample preparation to extract and clean up 
target compounds is generally required when chromatography-based technology is employed for the analysis of pesticide residues [5]. Classical solid-liquid extraction [6], solid-phase extraction (SPE) [7,8], matrix solid-phase dispersion (MSPD) [9], and dispersive solid-phase extraction (d-SPE) [10-12] methods have been developed for the determination of pesticides in bee pollen. Despite this progress, it is still a great challenge to develop a simple and rapid sample preparation method for residue analysis in bee pollen matrix. In the present work, we have proposed a new sample preparation procedure based on salting-out assisted liquid-liquid extraction [13] and disposable pipette extraction (DPX) clean-up for the determination of neonicotinoid residues in bee pollen.

DPX is an alternative solid-phase extraction (SPE) method which demonstrates the advantages of reducing labor, time, and solvent consumption in the clean-up of analytes [14,15]. In a typical DPX device, sorbents are assembled in a pipette tip with a screen at the bottom and a barrier on the top [16]. Sample solution may be introduced by drawing in from the bottom of the tip or loading on the top of it $[16,17]$. The analytes are then washed and eluted from the sorbent with a suitable solvent. The operation of DPX is simple and labor-saving. In addition, it allows for automated and high-throughput preparation when combined with the liquid handling system $[18,19]$. This sample preparation method has been widely used in the analysis of drugs [14,18-24], pesticide residues [16,17,25-30], heavy metal ions [31], and environmental contaminants [32-35]. In the present work, the parameters of DPX were systematically investigated on the clean-up of neonicotinoid pesticides in bee pollen. To the best of our knowledge, this is the first report on the use of the DPX method for the matrix of bee pollen.

\section{Results and Discussion}

\subsection{Salting-Out Assisted Liquid-Liquid Extraction}

A miniaturized salting-out assisted liquid-liquid extraction (mini-SALLE) was used for the rapid extraction of three neonicotinoid pesticides-thiamethoxam, acetamiprid, and thiacloprid-from bee pollen (Figure S1). In the mini-SALLE protocol, $2 \mathrm{~mL} \mathrm{ACN}$ mixed with $2 \mathrm{~mL} \mathrm{H}_{2} \mathrm{O}$ was applied as the extraction solution. The bee pollen sample was homogenized with the $\mathrm{ACN}-\mathrm{H}_{2} \mathrm{O}$ solution before phase separation agent was introduced to trigger the partition of $\mathrm{ACN}$ from the mixture. Salts, $0.4 \mathrm{~g}$ of $\mathrm{MgSO}_{4}$ and $0.2 \mathrm{~g}$ of $\mathrm{NaCl}$, were used to induce phase separation and extract target compounds into the upper ACN phase. The former, $\mathrm{MgSO}_{4}$, has been demonstrated to be an efficient phase-separation agent as the high extraction yield for relatively high-polarity compounds [36]. The latter, $\mathrm{NaCl}$, was used to reduce the co-extracted protein and sugar contents from the matrix $[37,38]$.

The obtained SALLE extract from the bee pollen showed a high background of matrix interferences. Bee pollen is a complex matrix which contains pigments, nutrients such as proteins, carbohydrates, vitamins, lipids, and various phytochemical compounds $[3,39,40]$. We observed that the final extract after SALLE (upper ACN phase) was still a light yellow color, though the phase partition had retained a substantial number of matrix compounds in the lower $\mathrm{H}_{2} \mathrm{O}$ phase. Moreover, as shown in Figure 1a, the diluted SALLE extract showed complicated and high-intensity chromatography peaks. It is important to note that the SALLE extract was diluted 50 times before being injected into the HPLC system to avoid damaging the HPLC column; therefore, the real response intensity of the extract would be tens of that shown in Figure 1a. It is also important to note that the gradient elution used in Figure 1a was previously reported for the separation of multiple phenolic compounds [36]. As shown in Figure 1b, this HPLC condition was also suitable for the separation of target neonicotinoid pesticides and the inner standard. Since bee pollen is a rich source of phenolic compounds [39,40], there are complicated peaks in the chromatogram of the SALLE extract; as a consequence, peaks of analytes could not be distinguished from the high background of interferences. This means that the SALLE extract required further clean-up to reduce interfering compounds. 


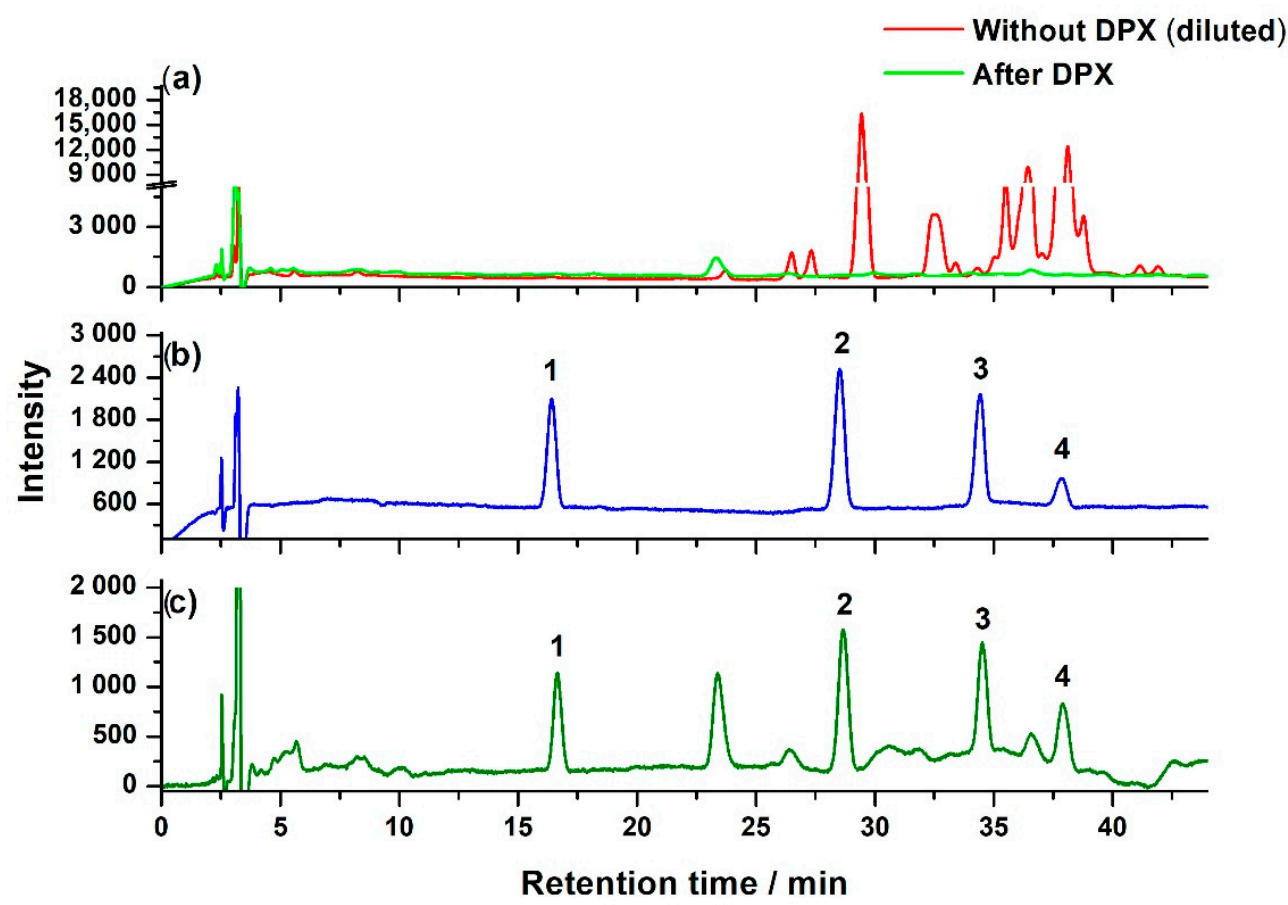

Figure 1. Representative chromatogram of (a) diluted SALLE extract without DPX and SALLE extract after PSA-based DPX, (b) standards of neonicotinoid pesticides and internal standard, (c) spiked bee pollen sample after SALLE and following PSA-based DPX clean-up. Peak 1: thiamethoxam, 2: acetamiprid, 3: thiacloprid, and 4: ethyl 6-chloropyridine-2-carboxylate (internal standard).

\subsection{DPX Clean-Up}

PSA-based DPX showed a simple, rapid, and efficient clean-up effect for neonicotinoid pesticides in bee pollen. It was interesting to observe that the extract solution became colorless after the PSA-based DPX clean-up. Furthermore, a chromatogram of the cleaned-up solution (Figure 1a) indicated that the intensity of the matrix interferences was dramatically reduced, while a good resolution of analytes with negligible interference was achieved (Figure 1c). These results indicate the excellent clean-up performance of DPX. To reveal the effect of DPX conditions, parameters were systematically investigated.

Different types of sorbents, including C18 and silica gel, were compared with PSA for clean-up efficiency. In the case of $\mathrm{C} 18$, cloudy solutions were obtained after both the loading and the eluting steps. After standing for minutes, sediments were observed in the bottom of the solutions; therefore, the cloudy extract was not further investigated in HPLC. In the silica gel DPX, the final eluent was transparent and colorless; its HPLC chromatogram is shown in Figure 2a. The result indicated that matrix compounds were also dramatically removed by silica gel DPX. Compared with the PSA-based DPX (Figure 1c), the matrix peak located at RT 23.54 min was much higher in silica gel DPX. In addition, peaks emerged at RT $18.08 \mathrm{~min}$ and $38.73 \mathrm{~min}$. More importantly, significant leakage of neonicotinoids was observed in the loading step of silica gel DPX, which led to the signal responses of analytes in Figure 2a that were only about $40 \%$ of that in PSA-based DPX (Figure 1c). These results indicated that PSA demonstrated better clean-up effect and analytes recovery than silica gel for the analysis of neonicotinoids in bee pollen. 


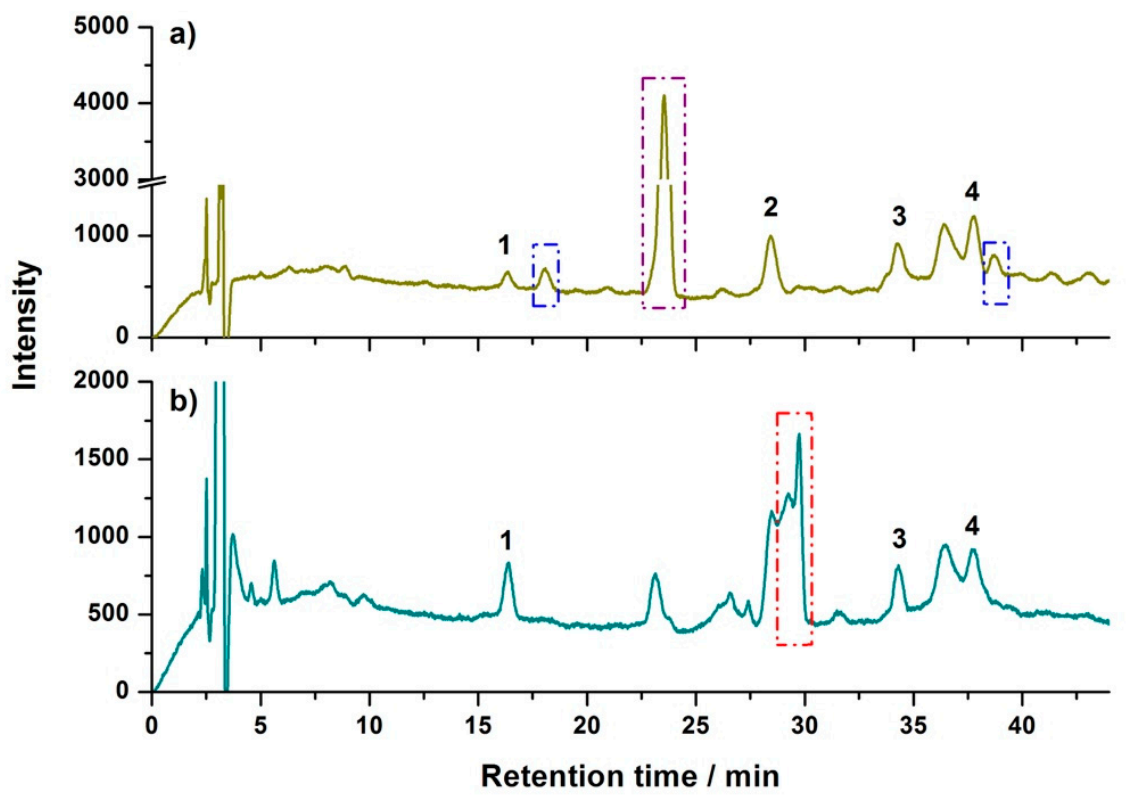

Figure 2. Representative chromatograms of extract cleaned up by (a) silica gel DPX, (b) dispersive solid-phase extraction (d-SPE). Peak 1: thiamethoxam, 2: acetamiprid, 3: thiacloprid, and 4: ethyl 6-chloropyridine-2-carboxylate (internal standard). The emerging peaks are marked in blue, the highintensity peak from the matrix is marked in purple, and the matrix peaks overlapped with acetamiprid after d-SPE are marked in red.

The effect of the mass of PSA was studied in the range from $50 \mathrm{mg}$ to $150 \mathrm{mg}$ with increments of $25 \mathrm{mg}$. It was found that when the mass was from $50 \mathrm{mg}$ to $100 \mathrm{mg}$, leakage of neonicotinoids was observed in the loading step, and the leaked content was increased with the decreasing of PSA mass. However, leaked analytes were not detected when the mass was further increased to $125 \mathrm{mg}$ and $150 \mathrm{mg}$. This implies that not less than $125 \mathrm{mg}$ of PSA would be required to prevent the leakage of neonicotinoids in the loading step. Additionally, the mass of PSA also affected the clean-up effect in the following elution step. As shown in Figure 3, in the DPX tips with $50 \mathrm{mg}$ and $75 \mathrm{mg}$ of PSA, peaks of matrix compounds were overlapped with acetamiprid. These interference compounds were eliminated when the mass of PSA was larger than $100 \mathrm{mg}$. However, as the mass increased to $150 \mathrm{mg}$, concentrations of neonicotinoids in the eluent were all slightly decreased, which might have resulted from the increasing retention of neonicotinoids in the larger mass of sorbent. Given the absence of analyte leaking in the loading step and its good performance in removing interferences, it was determined that $125 \mathrm{mg}$ of PSA is a suitable choice for the DPX tip.

Sample loading was investigated in two modes: draw-in and top-loading. For the draw-in mode, sample solution was aspirated into the DPX column from the bottom of the tip. For the top-loading mode, sample solution was loaded on the top of the DPX tip. In the draw-in mode, increasing the draw-in and dispense-out repeat times (in-out cycles) could improve the clean-up effect. As can be observed in Figure 4, as the in-out cycles increased from 1 to 3 the intensity of matrix compounds decreased significantly. However, the peaks of target compounds were still indistinguishable. In the top-loading mode, the chromatogram of the filtrate solution which was collected by dispensing the loading solution through the DPX tip was very clear and had extremely low levels of matrix compounds (Figure 4). This means that target compounds are all retained on the DPX column; thus, an eluting step is required to wash out the neonicotinoids. 


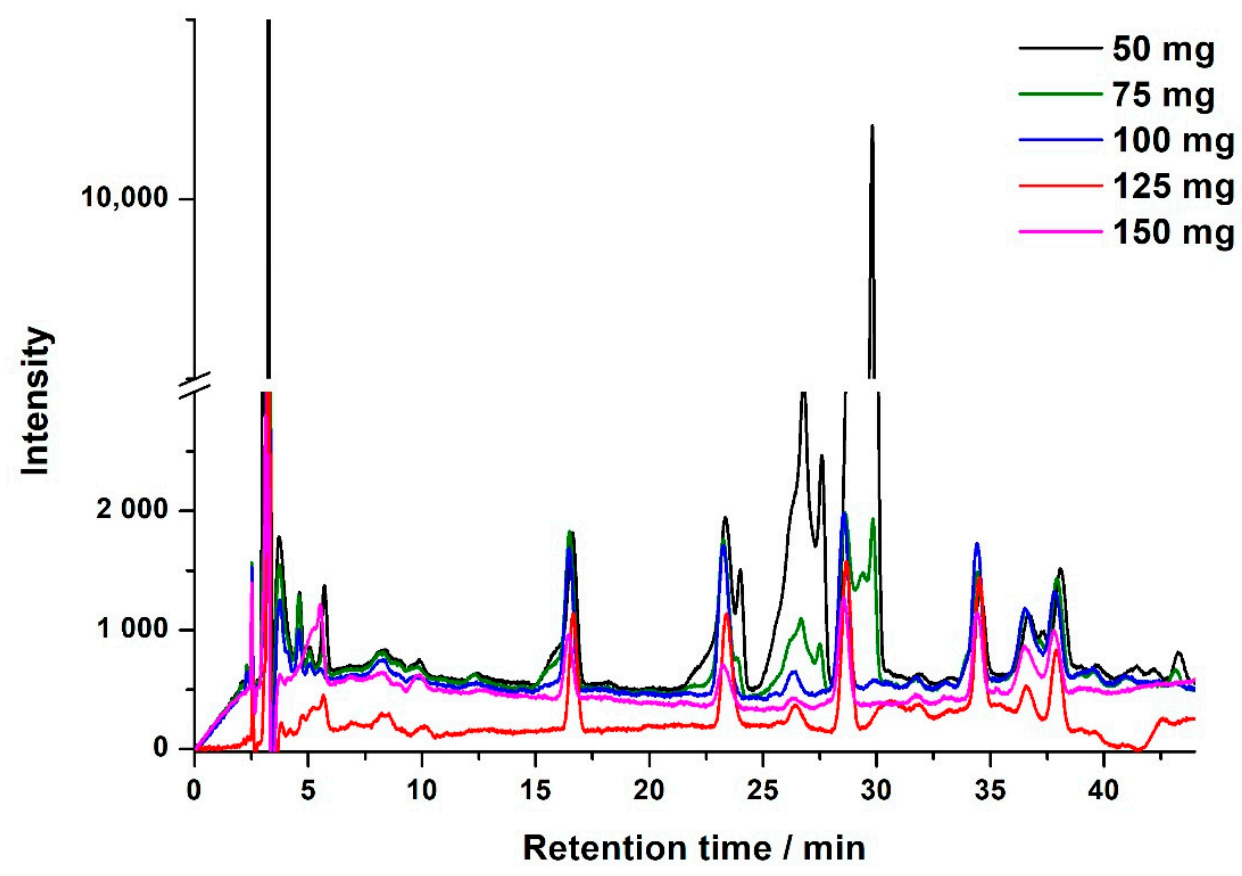

Figure 3. Representative chromatograms of extract cleaned up by DPX tips with different masses of PSA.

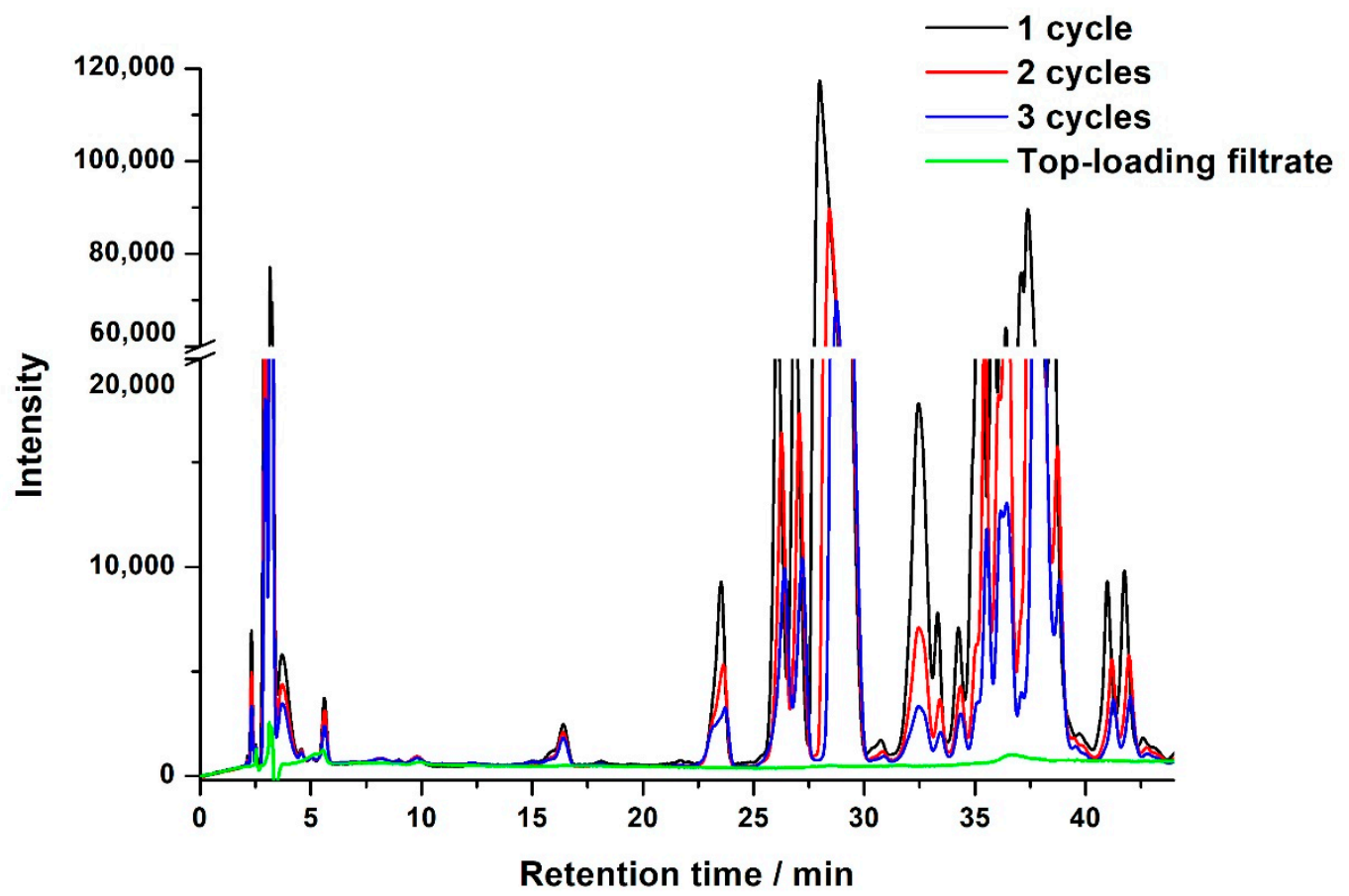

Figure 4. Representative chromatogram of the extract after different in-out cycles using draw-in sample loading, and the filtrate solution after top-loading.

After top-loading the extract, the target compounds were eluted by $100 \mu \mathrm{L}$ of $\mathrm{ACN}$ without a washing step. This elution solvent was also loaded on top of the DPX tip and then dispensed out of the DPX column. Different types of solutions, including $\mathrm{ACN}, \mathrm{MeOH}, \mathrm{H}_{2} \mathrm{O}$, and $\mathrm{ACN}-\mathrm{H}_{2} \mathrm{O}$ mixture $(25 \%, 50 \%, 75 \%, v / v)$, were investigated. The $\mathrm{MeOH}, \mathrm{H}_{2} \mathrm{O}$, and $\mathrm{ACN}-\mathrm{H}_{2} \mathrm{O}$ mixture all showed the co-elution of matrix interferences. Furthermore, as the $\mathrm{H}_{2} \mathrm{O}$ concentration increased, levels of interference compounds were significantly increased in the eluent. Different volumes of ACN were 
then compared, and $100 \mu \mathrm{L}$ was selected as the suitable volume since the further increase in volume would reduce the concentration of neonicotinoids in the eluent, and also increase the risk of the co-elution of matrix interferences.

On the basis of these investigations, the DPX device and the optimal DPX procedure can be proposed, as shown schematically in Figure 5. The DPX column was simply assembled in a $1 \mathrm{~mL}$ pipette tip, in which $125 \mathrm{mg}$ of PSA was used as the clean-up sorbent. After being conditioned with $300 \mu \mathrm{L}$ of ACN solution, $100 \mu \mathrm{L}$ of SALLE extract was loaded on top of the DPX tip. Then, $100 \mu \mathrm{L}$ of ACN was applied as the elution solution, which was also added on the top of the pipette tip. The elution was carried out by dispensing the ACN through the DPX column and collecting the eluent for HPLC analysis. The proposed DPX procedure was very simple and rapid; the whole operation could be accomplished in $2 \mathrm{~min}$, using a commercial pipette. Another advantage of the proposed method was the low consumption of sample and solvent, whose total volume was only $500 \mu \mathrm{L}$. This DPX method is eco-friendly and may have potential for use in green sample preparation.

a)

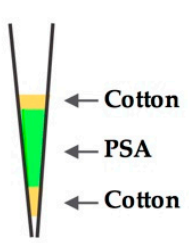

b)

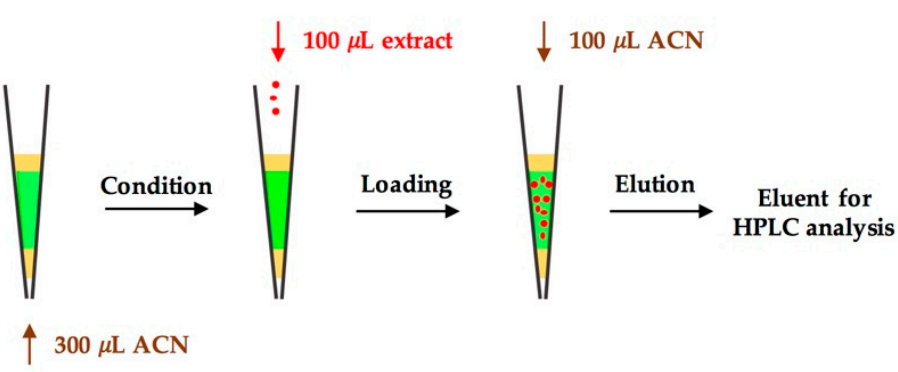

Figure 5. Schematic of (a) the DPX device, and (b) the optimal DPX procedure.

Finally, the developed DPX method was compared with the d-SPE procedure [41]. Due to the loss of solution in the d-SPE procedure, $100 \mu \mathrm{L}$ of SALLE extract was diluted with $300 \mu \mathrm{L}$ of ACN before being mixed with $125 \mathrm{mg}$ of PSA. As shown in Figure $2 \mathrm{~b}$, although the d-SPE procedure also showed significant removal of matrix compounds, its clean-up ability was less efficient than the DPX method, especially for acetamiprid, whose peak was still overlapped with interferences after the d-SPE clean-up.

\subsection{Analytical Performance}

The final cleaned-up solution was separated in C18 reversed-phase HPLC with gradient elution. Target neonicotinoid pesticides were quantified by an inner standard based on our previous report [42]. The diode array detector (DAD) was used for the detection of pesticides, and a wavelength of $254 \mathrm{~nm}$ was applied for the quantification. Standards curves were in the linearity range from 0.05 to $3 \mu \mathrm{g} / \mathrm{mL}$. The detection limit and quantification limit for the analytes were $100 \mu \mathrm{g} / \mathrm{kg}$ and $300 \mu \mathrm{g} / \mathrm{kg}$ with signal to noise of 3 and 10, respectively. The accuracy and precision at two spiked levels $(1 \times$ LOQ, $5 \times$ LOQ $)$ are shown in Table 1. Recoveries were between 89.63 and $94.56 \%, 96.41$ and $100.85 \%$, and 86.49 and $96.62 \%$ for thiamethoxam, acetamiprid, and thiacloprid, respectively. Intra-day and inter-day precisions were all less than $5 \%$. These results were all in the acceptable range according to the Association of Official Analytical Chemist (AOAC) [43]. Finally, six commercial bee pollen samples were analyzed using the validated method. Results indicated that none of the target neonicotinoid pesticides was detected in these samples. Due to the DPX procedure's excellent clean-up performance in removing matrix interferences, detection sensitivity towards neonicotinoid pesticides could be significantly improved 
by combining this simple and rapid DPX method with mass spectrometry detection. These studies are now under way.

Table 1. Accuracy and precision of the proposed method at two spiked levels.

\begin{tabular}{|c|c|c|c|c|c|c|c|c|c|}
\hline \multirow{3}{*}{ Analytes } & \multirow{3}{*}{$\begin{array}{c}\text { Spiked } \\
\text { Level } \\
(\mu \mathrm{g} / \mathrm{kg})\end{array}$} & \multicolumn{6}{|c|}{ Intra-Day } & \multicolumn{2}{|c|}{ Inter-Day } \\
\hline & & \multicolumn{2}{|c|}{ Day 1} & \multicolumn{2}{|c|}{ Day 2} & \multicolumn{2}{|c|}{ Day 3} & \multirow{2}{*}{$\begin{array}{r}\text { Mean } \pm \text { SD } \\
(\%, n=18)\end{array}$} & \multirow{2}{*}{$\begin{array}{c}\text { RSD } \\
(\%, n=18)\end{array}$} \\
\hline & & $\begin{array}{c}\text { Mean } \pm \text { SD } \\
(\%, n=6)\end{array}$ & $\begin{array}{c}\text { RSD } \\
(\%, n=6)\end{array}$ & $\begin{array}{c}\text { Mean } \pm \text { SD } \\
(\%, n=6)\end{array}$ & $\begin{array}{c}\text { RSD } \\
(\%, n=6)\end{array}$ & $\begin{array}{c}\text { Mean } \pm \text { SD } \\
(\%, n=6)\end{array}$ & $\begin{array}{c}\text { RSD } \\
(\%, n=6)\end{array}$ & & \\
\hline \multirow{2}{*}{ Thiamethoxam } & 300 & $94.56 \pm 4.18$ & 4.42 & $92.61 \pm 3.01$ & 3.25 & $89.63 \pm 2.26$ & 2.52 & $92.26 \pm 3.70$ & 4.01 \\
\hline & 1500 & $92.40 \pm 3.46$ & 3.74 & $91.81 \pm 3.68$ & 4.01 & $89.70 \pm 3.46$ & 3.86 & $91.30 \pm 3.53$ & 3.87 \\
\hline \multirow{2}{*}{ Acetamiprid } & 300 & $99.13 \pm 2.86$ & 2.89 & $97.82 \pm 2.25$ & 2.30 & $98.18 \pm 3.77$ & 3.84 & $98.38 \pm 2.89$ & 2.94 \\
\hline & 1500 & $97.24 \pm 3.11$ & 3.20 & $96.41 \pm 2.63$ & 2.73 & $100.85 \pm 3.11$ & 3.08 & $98.17 \pm 3.42$ & 3.48 \\
\hline \multirow{2}{*}{ Thiacloprid } & 300 & $86.49 \pm 3.81$ & 4.41 & $86.58 \pm 3.36$ & 3.88 & $87.68 \pm 3.31$ & 3.78 & $86.92 \pm 3.49$ & 4.02 \\
\hline & 1500 & $93.29 \pm 3.99$ & 4.28 & $92.96 \pm 3.38$ & 3.64 & $96.62 \pm 1.95$ & 2.02 & $94.29 \pm 3.47$ & 3.68 \\
\hline
\end{tabular}

\section{Materials and Methods}

\subsection{Materials}

Methanol and acetonitrile (ACN) at HPLC grade were obtained from Merck (Darmstadt, Germany). Acetic acid, anhydrous magnesium sulfate, and sodium chloride at analytical grade were obtained from Sinopharm Chemical Reagent Co., Ltd. (Shanghai, China). Standards of thiamethoxam, acetamiprid, thiacloprid, and ethyl 6-chloropyridine-2-carboxylate (internal standard) were supplied by Aladdin (Shanghai, China). C18 and PSA were from Sepax (Suzhou, China), and silica gel was from Sinopharm. Ultrapure water (18.2 M $)$ was used in all experiments. Rape (Brassica campestris) bee pollen used for method development was collected from an apiary in Hubei, China. Commercial rape bee pollen samples used in this application were purchased from local markets. Stock solutions of standards were prepared in ACN with a concentration of $0.2 \mathrm{mg} / \mathrm{mL}$. Working solutions of standards were prepared by further dilution with ACN. All standard solutions were stored at $4{ }^{\circ} \mathrm{C}$ until used.

\subsection{Salting-Out Assisted Liquid-Liquid Extraction}

Bee pollen $(1 \mathrm{~g})$ was added into $4 \mathrm{~mL}$ of $\mathrm{ACN}-\mathrm{H}_{2} \mathrm{O}$ solution $(1: 1, v / v)$, then the mixture was homogenized for $30 \mathrm{~s}$ by a homogenizer (Fluko, China). After the addition of salts (0.4 $\mathrm{g} \mathrm{MgSO}_{4}$ and $0.2 \mathrm{~g} \mathrm{NaCl}$ ), the obtained mixture was vortexed for $30 \mathrm{~s}$ to dissolve the salts. Then, the final solution was centrifuged at $5000 \mathrm{rpm}$ for $10 \mathrm{~min}$ to make phase separation clear. The upper phase was collected for DPX clean-up.

\subsection{DPX Clean-Up}

DPX was assembled in a commercial pipette tip $(1 \mathrm{~mL})$. Briefly, PSA (125 mg) was transferred into the pipette tip, with degreasing cotton preloaded at the tip exit for retaining the sorbent. Another pellet of degreasing cotton was then placed on top of the sorbent.

The obtained DPX tip was conditioned with $300 \mu \mathrm{L}$ of ACN, which was aspirated into the tip from the bottom with an aspiration volume of $800 \mu \mathrm{L}$ to draw in extra air bubbles for mixing. After bubbling was completed, the solution was dispensed to waste.

Then, $100 \mu \mathrm{L}$ of SALLE extract was added to the top of the DPX tip and dispensed through the sorbent for sample loading. Finally, $100 \mu \mathrm{L}$ of ACN was added to the top of the DPX tip and dispensed to elute target compounds. The eluent was collected and transferred into a vial for HPLC analysis.

\subsection{Study of DPX Procedure}

\subsubsection{Comparing Matrix Solution without DPX Clean-Up}

The SALLE extract $(100 \mu \mathrm{L})$ was diluted 50 times with the $\mathrm{ACN}-\mathrm{H}_{2} \mathrm{O}$ mixture $(50 \%, v / v)$ before HPLC analysis. 


\subsubsection{Effect of Different Sorbents}

DPX tips were assembled with $125 \mathrm{mg}$ of C18 or silica gel, and the clean-up was then performed as described in Section 3.3.

\subsubsection{Effect of the Mass of PSA}

DPX tips were assembled with different masses of PSA (50, 75, 100, 125, and $150 \mathrm{mg})$. Then, the filtrate solution after sample loading and the final eluent solution as described in Section 3.3 were collected for HPLC analysis.

\subsubsection{Effect of Elution Solvent}

DPX tips were assembled with $125 \mathrm{mg}$ of PSA. Clean-up was then performed as described in Section 3.3 with different elution solvents, including $\mathrm{MeOH}, \mathrm{H}_{2} \mathrm{O}$, and $\mathrm{ACN}-\mathrm{H}_{2} \mathrm{O}$ mixtures $(25 \%, 50 \%$, $75 \%, v / v)$.

\subsubsection{Comparing Draw-In Sample Loading Mode}

DPX tips assembled with $125 \mathrm{mg}$ of PSA were conditioned as described in Section 3.3. Then, $100 \mu \mathrm{L}$ of SALLE extract was aspirated into the DPX tip from the bottom with an aspiration volume of $800 \mu \mathrm{L}$. After bubbling was completed, the solution was dispensed through the sorbent and collected in another tube. This aspirating in-out operation was repeated three times, and solutions in different cycles were collected for HPLC analysis.

\subsubsection{Comparing d-SPE}

The d-SPE clean-up experiment was performed on the basis of the reported method [41]. Because of the loss of volume to the sorbent in the d-SPE method, $100 \mu \mathrm{L}$ of the SALLE extract was diluted with $300 \mu \mathrm{L}$ of ACN before being mixing with sorbent. The diluted solution was mixed with $125 \mathrm{mg}$ of PSA and vortexed for $1 \mathrm{~min}$. The mixture was then centrifuged at $5000 \mathrm{rpm}$ for $10 \mathrm{~min}$. After centrifugation, the supernatant was collected for HPLC analysis.

\subsection{HPLC Analysis}

HPLC analysis was performed on Shimadzu (Kyoto, Japan) LC-20AT, with a SIL-20AC autosampler, CTO-20AC column oven, and SPD-M20A photodiode array detector. A TSKgel (Tosoh, Japan) ODS-100V column $(5 \mu \mathrm{m}, 4.6 \times 150 \mathrm{~mm})$ was applied for the separation. The previously reported gradient elution $[36,44]$ was modified for the separation of neonicotinoids. Solvent A was water with $0.1 \%$ acetic acid $(v / v)$, and solvent $B$ was methanol. Elution was as follows: $15 \%$ to $40 \%$ solvent B at $0-30 \mathrm{~min}$, $40 \%$ to $46 \%$ solvent B at 30-44 min, post run with $46 \%$ to $100 \%$ solvent $B$ for $6 \mathrm{~min}$, then back to and maintained at $15 \%$ solvent $B$, each for $5 \mathrm{~min}$. The column temperature was set at $35^{\circ} \mathrm{C}$, the injection volume was $10 \mu \mathrm{L}$, the flow rate was $0.8 \mathrm{~mL} / \mathrm{min}$, and the detection wavelength was $254 \mathrm{~nm}$.

\subsection{Method Validation}

Seven levels of calibration curves were prepared by standard solutions containing neonicotinoid pesticides $(0.05,0.1,0.2,0.5,1,2,3 \mu \mathrm{g} / \mathrm{mL})$ and IS $(2 \mu \mathrm{g} / \mathrm{mL})$. The ratio of peak area (analyte/IS) versus the ratio of weight (analyte/IS) was used to construct the analytical curves. The y-intercept was set to zero and a linear fit was performed. Limit of detection (LOD) and limit of quantification (LOQ) were investigated in spiked bee pollen samples. Accuracy and precision were estimated by analyzing blank samples spiked at concentrations of $1 \times$ LOQ and $5 \times$ LOQ. Accuracy was expressed as recovery (\%), and precision was measured as relative standard deviation (RSD) to the mean recovery of intra-day $(n=6)$ and inter-day ( $n=18$, three days) analyses. 


\section{Conclusions}

In summary, a DPX sample preparation method was developed for the HPLC analysis of neonicotinoid pesticides in bee pollen. Effects of the DPX parameters on the clean-up efficiency were systematically investigated. Results revealed that using PSA as the DPX sorbent, combined with top-loading of the sample into the pipette tip and elution, resulted in a remarkable removal of matrix interferences. This PSA-based DPX method exhibited excellent clean-up ability with the merits of simple, rapid, and low solvent consumption. The present work might provide a new strategy for designing fast sample preparation procedures for the challenging and important bee pollen matrix.

Supplementary Materials: The following are available online, Figure S1: Structures and LogP values of analytes.

Author Contributions: Conceptualization, X.T. and W.C.; Investigation, X.T. and W.C.; Methodology, W.C.; Writing-original draft, W.C.; Writing-review \& editing, X.T. and W.C. Both authors have read and agreed to the published version of the manuscript.

Funding: This work was funded by Natural Science Foundation of Fujian Province (NO.2020J01535, NO.2019J01409).

Conflicts of Interest: The authors declare no conflict of interest.

\section{References}

1. Neumann, P.; Carreck, N.L. Honey bee colony losses. J. Apic. Res. 2010, 49, 1-6. [CrossRef]

2. Goulson, D.; Nicholls, E.; Botías, C.; Rotheray, E.L. Bee declines driven by combined stress from parasites, pesticides, and lack of flowers. Science 2015, 347, 1255957. [CrossRef]

3. Campos, M.R.G.; Bogdanov, S.; de Almeida-Muradian, L.M.B.; Szczesna, T.; Mancebo, Y.; Frigerio, C.; Ferreira, F. Pollen composition and standardisation of analytical methods. J. Apicult. Res. 2008, 47, $156-163$. [CrossRef]

4. Mao, W.; Schuler, M.A.; Berenbaum, M.R. Honey constituents up-regulate detoxification and immunity genes in the western honey bee Apis mellifera. Proc. Natl. Acad. Sci. USA 2013, 110, 8842-8846. [CrossRef] [PubMed]

5. Tu, X.; Chen, W. Overview of Analytical Methods for the Determination of Neonicotinoid Pesticides in Honeybee Products and Honeybee. Crit. Rev. Anal. Chem. 2020, in press. [CrossRef] [PubMed]

6. Yáñez, K.P.; Martín, M.T.; Bernal, J.L.; Nozal, M.J. Trace Analysis of Seven Neonicotinoid Insecticides in Bee Pollen by Solid-Liquid Extraction and Liquid Chromatography Coupled to Electrospray Ionization Mass Spectrometry. Food Anal. Methods 2014, 7, 490-499. [CrossRef]

7. Zhang, L.; Wang, Y.; Sun, C.; Yang, S.; He, H. Simultaneous Determination of Organochlorine, Organophosphorus, and Pyrethroid Pesticides in Bee Pollens by Solid-Phase Extraction Cleanup Followed by Gas Chromatography Using Electron-Capture Detector. Food Anal. Methods 2012, 6, 1508-1514. [CrossRef]

8. López-Fernández, O.; Rial-Otero, R.; Simal-Gándara, J. High-throughput HPLC-MS/MS determination of the persistence of neonicotinoid insecticide residues of regulatory interest in dietary bee pollen. Anal. Bioanal. Chem. 2015, 407, 7101-7110. [CrossRef]

9. Vazquez-Quintal, P.E.; Rodríguez, D.M.; Medina-Peralta, S.; Moguel-Ordóñez, Y.B. Extraction of Organochlorine Pesticides from Bee Pollen by Matrix Solid-Phase Dispersion: Recovery Evaluation by GC-MS and Method Validation. Chromatographia 2012, 75, 923-930. [CrossRef]

10. Vázquez, P.P.; Lozano, A.; Uclés, S.; Ramos, M.G.; Fernández-Alba, A.R. A sensitive and efficient method for routine pesticide multiresidue analysis in bee pollen samples using gas and liquid chromatography coupled to tandem mass spectrometry. J. Chromatogr. A 2015, 1426, 161-173. [CrossRef]

11. Li, Y.; Kelley, R.A.; Anderson, T.D.; Lydy, M. Development and comparison of two multi-residue methods for the analysis of select pesticides in honey bees, pollen, and wax by gas chromatography-quadrupole mass spectrometry. Talanta 2015, 140, 81-87. [CrossRef] [PubMed]

12. Bernal, J.; Nozal, M.J.; Martín, M.T.; Bernal, J.L.; Ares, A.M. Trace analysis of flubendiamide in bee pollen using enhanced matrix removal-lipid sorbent clean-up and liquid chromatography-electrospray ionization mass spectrometry. Microchem. J. 2019, 148, 541-547. [CrossRef] 
13. Valente, I.M.; Rodrigues, J.A. Recent advances in salt-assisted LLE for analyzing biological samples. Bioanalysis 2015, 7, 2187-2193. [CrossRef] [PubMed]

14. Schroeder, J.L.; Marinetti, L.J.; Smith, R.K.; Brewer, W.E.; Clelland, B.L.; Morgan, S.L. The analysis of delta9-tetrahydrocannabinol and metabolite in whole blood and 11-nor-delta9-tetrahydrocannabinol-9carboxylic acid in urine using disposable pipette extraction with confirmation and quantification by gas chromatography-mass spectrometry. J. Anal. Toxicol. 2008, 32, 659-666. [CrossRef] [PubMed]

15. Bordin, D.C.M.; Alves, M.N.R.; De Campos, E.G.; De Martinis, B.S. Disposable pipette tips extraction: Fundamentals, applications and state of the art. J. Sep. Sci. 2016, 39, 1168-1172. [CrossRef]

16. Guan, H.; Brewer, W.E.; Garris, S.T.; Morgan, S.L. Disposable pipette extraction for the analysis of pesticides in fruit and vegetables using gas chromatography/mass spectrometry. J. Chromatogr. A 2010, 1217, 1867-1874. [CrossRef]

17. Guan, H.; Brewer, W.E.; Morgan, S.L. New Approach to Multiresidue Pesticide Determination in Foods with High Fat Content Using Disposable Pipette Extraction (DPX) and Gas Chromatography-Mass spectrometry (GC-MS). J. Agric. Food Chem. 2009, 57, 10531-10538. [CrossRef]

18. Scheidweiler, K.B.; Newmeyer, M.N.; Barnes, A.J.; Huestis, M.A. Quantification of cannabinoids and their free and glucuronide metabolites in whole blood by disposable pipette extraction and liquid chromatography-tandem mass spectrometry. J. Chromatogr. A 2016, 1453, 34-42. [CrossRef]

19. Mastrianni, K.R.; Metavarayuth, K.; Brewer, W.E.; Wang, Q. Analysis of $10 \beta$-agonists in pork meat using automated dispersive pipette extraction and LC-MS/MS. J. Chromatogr. B 2018, 1084, 64-68. [CrossRef]

20. Bordin, D.C.M.; Alves, M.N.; Cabrices, O.G.; De Campos, E.G.; De Martinis, B.S. A Rapid Assay for the Simultaneous Determination of Nicotine, Cocaine and Metabolites in Meconium Using Disposable Pipette Extraction and Gas Chromatography-Mass Spectrometry (GC-MS). J. Anal. Toxicol. 2013, 38, 31-38. [CrossRef]

21. Pinto, M.A.L.; De Souza, I.D.; Queiroz, M.E.C. Determination of drugs in plasma samples by disposable pipette extraction with C18-BSA phase and liquid chromatography-tandem mass spectrometry. J. Pharm. Biomed. Anal. 2017, 139, 116-124. [CrossRef] [PubMed]

22. Samanidou, V.F.; Stathatos, C.; Njau, S.; Kovatsi, L. Disposable pipette extraction for the simultaneous determination of biperiden and three antipsychotic drugs in human urine by GC-nitrogen phosphorus detection. Bioanalysis 2013, 5, 21-29. [CrossRef] [PubMed]

23. Lehotay, S.J.; Mastovska, K.; Lightfield, A.R.; Nuñez, A.; Dutko, T.; Ng, C.; Bluhm, L. Rapid analysis of aminoglycoside antibiotics in bovine tissues using disposable pipette extraction and ultrahigh performance liquid chromatography-tandem mass spectrometry. J. Chromatogr. A 2013, 1313, 103-112. [CrossRef] [PubMed]

24. Chaves, A.R.; Moura, B.H.; Caris, J.A.; Rabelo, D.; Queiroz, M.E.C. The development of a new disposable pipette extraction phase based on polyaniline composites for the determination of levels of antidepressants in plasma samples. J. Chromatogr. A 2015, 1399, 1-7. [CrossRef] [PubMed]

25. Oenning, A.L.; Merib, J.; Carasek, E. An effective and high-throughput analytical methodology for pesticide screening in human urine by disposable pipette extraction and gas chromatography-mass spectrometry. J. Chromatogr. B 2018, 1092, 459-465. [CrossRef] [PubMed]

26. Zhang, H.; Li, Y.; Zhu, J.; Li, H.; Li, D.; Liu, Z.; Sun, X.; Wang, B.; Wang, Q.; Gao, Y. Disposable Pipette Extraction (DPX) Coupled with Liquid Chromatography-Tandem Mass Spectrometry for the Simultaneous Determination of Pesticide Residues in Wine Samples. Food Anal. Methods 2019, 12, 2262-2272. [CrossRef]

27. Júnior, C.A.S.A.; Dos Santos, A.L.R.; De Faria, A.M. Disposable pipette extraction using a selective sorbent for carbendazim residues in orange juice. Food Chem. 2020, 309, 125756. [CrossRef]

28. Tan, S.C.; Lee, H.K. Graphitic carbon nitride as sorbent for the emulsification-enhanced disposable pipette extraction of eight organochlorine pesticides prior to GC-MS analysis. Microchim. Acta 2020, 187, 1-10. [CrossRef]

29. Fernandes, V.C.; Domingues, V.F.; Mateus, N.; Delerue-Matos, C. Multiresidue pesticides analysis in soils using modified QuEChERS with disposable pipette extraction and dispersive solid-phase extraction. J. Sep. Sci. 2012, 36, 376-382. [CrossRef]

30. Lu, Z.; Fang, N.; Zhang, Z.; Hou, Z.; Lu, Z.; Li, Y. Residue analysis of fungicides fenpicoxamid, isofetamid, and mandestrobin in cereals using zirconium oxide disposable pipette extraction clean-up and ultrahigh-performance liquid chromatography-tandem mass spectrometry. J. Chromatogr. A 2020, 1620, 461004. [CrossRef] 
31. Cadorim, H.R.; Schneider, M.; Hinz, J.; Luvizon, F.; Dias, A.N.; Carasek, E.; Welz, B. Effective and High-Throughput Analytical Methodology for the Determination of Lead and Cadmium in Water Samples by Disposable Pipette Extraction Coupled with High-Resolution Continuum Source Graphite Furnace Atomic Absorption Spectrometry (HR-CS GF AAS). Anal. Lett. 2019, 52, 2133-2149. [CrossRef]

32. Corazza, G.; Merib, J.; Magosso, H.A.; Bittencourt, O.R.; Carasek, E. A hybrid material as a sorbent phase for the disposable pipette extraction technique enhances efficiency in the determination of phenolic endocrine-disrupting compounds. J. Chromatogr. A 2017, 1513, 42-50. [CrossRef] [PubMed]

33. Morés, L.; Da Silva, A.C.; Merib, J.; Dias, A.N.; Carasek, E. A natural and renewable biosorbent phase as a low-cost approach in disposable pipette extraction technique for the determination of emerging contaminants in lake water samples. J. Sep. Sci. 2019, 42, 1404-1411. [CrossRef] [PubMed]

34. Turazzi, F.C.; Morés, L.; Carasek, E.; Merib, J.; Barra, G.M.D.O. A rapid and environmentally friendly analytical method based on conductive polymer as extraction phase for disposable pipette extraction for the determination of hormones and polycyclic aromatic hydrocarbons in river water samples using high-performance liquid chromatography/diode array detection. J. Environ. Chem. Eng. 2019, 7, 103156. [CrossRef]

35. Pena-Abaurrea, M.; De La Torre, V.G.; Ramos, L.; De La Torre, V.S.G. Ultrasound-assisted extraction followed by disposable pipette purification for the determination of polychlorinated biphenyls in small-size biological tissue samples. J. Chromatogr. A 2013, 1317, 223-229. [CrossRef] [PubMed]

36. Chen, W.; Tu, X.; Wu, D.; Gao, Z.; Wu, S.; Huang, S. Comparison of the Partition Efficiencies of Multiple Phenolic Compounds Contained in Propolis in Different Modes of Acetonitrile-Water-Based Homogenous Liquid-Liquid Extraction. Molecules 2019, 24, 442. [CrossRef] [PubMed]

37. Tu, X.; Sun, F.; Wu, S.; Liu, W.; Gao, Z.; Huang, S.; Chen, W. Comparison of salting-out and sugaring-out liquid-liquid extraction methods for the partition of 10-hydroxy-2-decenoic acid in royal jelly and their co-extracted protein content. J. Chromatogr. B 2018, 1073, 90-95. [CrossRef] [PubMed]

38. Chen, W.; Wu, S.; Zhang, J.; Yu, F.; Miao, X.; Tu, X. Salting-out-assisted liquid-liquid extraction of 5-hydroxymethylfurfural from honey and the determination of 5-hydroxymethylfurfural by high-performance liquid chromatography. Anal. Methods 2019, 11, 4835-4841. [CrossRef]

39. Zhou, J.; Qi, Y.; Ritho, J.; Zhang, Y.; Zheng, X.; Wu, L.; Li, Y.; Sun, L. Flavonoid glycosides as floral origin markers to discriminate of unifloral bee pollen by LC-MS/MS. Food Control 2015, 57, 54-61. [CrossRef]

40. Tu, X.; Ma, S.; Gao, Z.; Wang, J.; Huang, S.; Chen, W. One-Step Extraction and Hydrolysis of Flavonoid Glycosides in Rape Bee Pollen Based on Soxhlet-Assisted Matrix Solid Phase Dispersion. Phytochem. Anal. 2017, 28, 505-511. [CrossRef] [PubMed]

41. Anastassiades, M.; Lehotay, S.J.; Štajnbaher, D.; Schenck, F.J. Fast and Easy Multiresidue Method Employing Acetonitrile Extraction/Partitioning and "Dispersive Solid-Phase Extraction" for the Determination of Pesticide Residues in Produce. J. AOAC Int. 2003, 86, 412-431. [CrossRef] [PubMed]

42. Chen, W.; Wu, S.; Zhang, J.; Yu, F.; Hou, J.; Miao, X.; Tu, X. Matrix-Induced Sugaring-Out: A Simple and Rapid Sample Preparation Method for the Determination of Neonicotinoid Pesticides in Honey. Molecules 2019, 24, 2761. [CrossRef] [PubMed]

43. Taverniers, I.; De Loose, M.; Van Bockstaele, E. Trends in quality in the analytical laboratory. II. Analytical method validation and quality assurance. TrAC Trends Anal. Chem. 2004, 23, 535-552. [CrossRef]

44. Zhang, C.-P.; Huang, S.; Wei, W.-T.; Shun, P.; Shen, X.-G.; Li, Y.-J.; Hu, F.-L. Development of High-Performance Liquid Chromatographic for Quality and Authenticity Control of Chinese Propolis. J. Food Sci. 2014, 79, C1315-C1322. [CrossRef]

Sample Availability: Not available.

Publisher's Note: MDPI stays neutral with regard to jurisdictional claims in published maps and institutional affiliations.

(C) 2020 by the authors. Licensee MDPI, Basel, Switzerland. This article is an open access article distributed under the terms and conditions of the Creative Commons Attribution (CC BY) license (http://creativecommons.org/licenses/by/4.0/). 